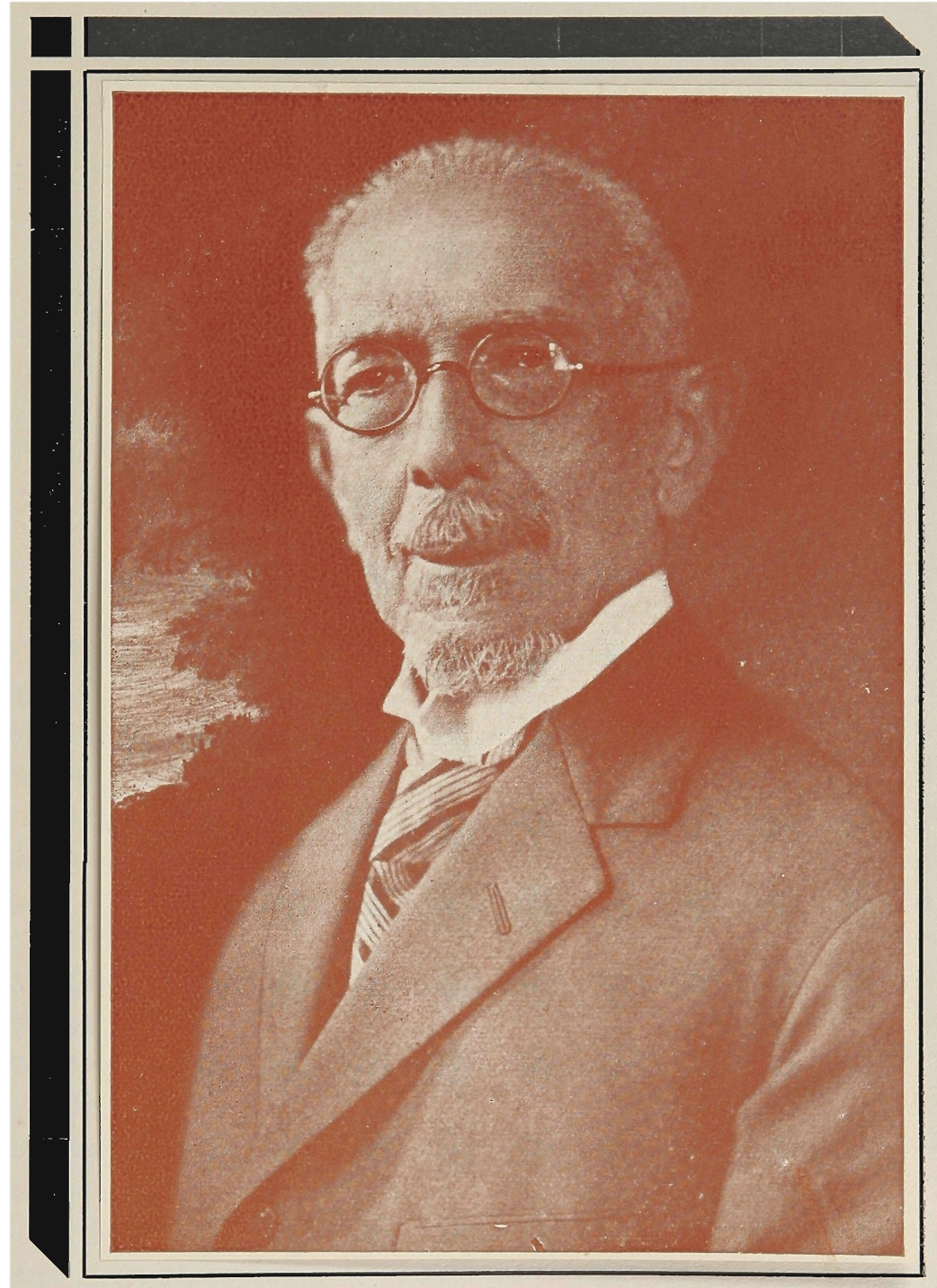

Antonio Dino da Costa Bueno 


\section{Antonio Dino da Costa Bueno}

Nasceu Antonio Dino da Costa Bueno aos 15 de dezembro de 1854 na nobre e generosa terra de Pindamonhangaba, na então provincia de São Paulo. Ali nasceu e ali fez os seus estudos preliminares, distinguindo-se na escola dirigida por Manuel Cunha Matos e, depois, no Colegio Pindamonhangabense, instituto de ensino secundario fundado pelo professor Miguel José Cardoso.

Transportou-se, em 1866, para a Côrte, onde cursou os estudos secundarios, no Colegio Episcopal de S. Pedro d'Alcantara, no Palacio do Rio Comprido, sob a direção dos Reverendissimos Padres Paivas.

De como foi criado e educado, disse-o ele em seu testamento cerrado, em palavras da mais comovedora piedade e exaltação:

"Fui criado por D. Constança Dina do Amor Divino tipo de mulher forte - e mãi do sempre benemerito Conego Tobias da Costa Rezende, e por este sustentado em meus estudos, primeiro no Rio de Janeiro, e depois em S. Paulo. Deles recebi, desde a minha infancia, o sentimento da digni- 
dade, o amor da independencia, a paixão do trabalho; com eles aprendi os são principios da moral civica e privada. E sempre procurei guarda-los em toda a minha vida, ao que, creio firmemente, devo a felicidade de que, mercê de Deus, tenho gosado, quer no seio da familia, quer na sociedade em que tenho tido a fortuna de viver. Para, em minha vida, cultuar-lhe a memoria, adquiri, por compra, a casa e chacara do Conego Tobias, nesta cidade (Pindamonhangaba), por ele fundada, plantada e beneficiada, e, com todos os moveis e ornatos, a tenho conservado desde o seu falecimento em 7 de agosto de 1898 até o presente, guardando-lhe, quanto possivel, a feição, com que existia, ao tempo de sua vida, e dando-me a impressão de que ainda vive aquele grande espirito, que tanto serviu e dignificou a terra em que nasceu, e a Patria, a que tanto amou".

Terminados os estudos secundarios, transferiu-se para São Paulo, matriculando-se na Faculdade de Direito.

"Na Academia", escreveu José Luiz de Almeida NogueiRA, num dos volumes de suas cronicas academicas, "foi sempre muito aplicado, tendo, porém, começado a salientar-se somente do $3 .^{\circ}$ ano em diante. Tanto assim que, por ocasião dos atos (chamavam-se, a esse tempo, atos aos exames) do $2 .^{\circ}$, tendo alcançado a nota "otima" somente numa prova escrita (eram anonimas, nesse tempo) conjeturaram os lentes que a prova fosse do Teixeira da Mota. E esta noticia se propalou. Verificou-se depois que o estudante assim laureado era o Dino Bueno. Aprovado com distinção, daí por diante em todos os seus atos, não o foi no do $5 .^{\circ}$ ano, porque não era tradição dar-se naquele ano tal grau de aprovação. Isto mesmo foi alegado por um dos examinadores, o Conselheiro Funtado, cuja opinião prevaleceu por ser a de um catedratico, contra a dos outros dois, conselheiro Duarte de Azevedo e Dr. Vieira de Carvalho".

Bacharelou-se em 1875.

Promotor da Justiça Publica na Capital da Provincia de São Paulo, em janeiro de 1876 , no mesmo ano se propôs defender teses. E foi aprovado. Recebeu, no dia 9 de no- 
vembro de 1876, o grau de Doutor em Direito, proferindo, em Congregação, o discurso neste mesmo volume reproduzido. Nas festas do seu jubileu doutoral, em 9 de novembro de 1926, referiu porque, apenas bacharel formado, quiz alcançar o doutorado:

"Circunstancias academicas, ocorridas no decurso do meu segundo ano de estudos, deixaram assentado, em meu espirito, o proposito firme e decidido de conquistar, pelo meu esforço, o grau de doutor e, em seguida, uma cadeira de lente na Faculdade de Direito.

Era uma verdadeira temeridade do meu espirito: difficilima era a defesa de teses, necessaria ao doutoramento, teses que deviam ser redigidas sobre todas as materias, ou disciplinas, do curso de Direito, e, em ato publico e solene, sustentadas diante de arguição de lentes da Faculdade; honra excecional era a colação do grau de doutor, e a muitos poucos, verdadeiros privilegiados, era conferida.

Entretanto, eu havia assentado esse proposito, quando apenas iniciava os meus dezesete anos de idade. Sem familia valerosa, e sem recursos, dificilimo ser-me-ia realiza-lo; mas a minha isorte estava lançada - alea jacta est; e, para ela, eu só podia contar com o meu proprio esforço.

Receoso de fracasso, a ninguem revelei o meu proposito, nem mesmo a pessôa de minha familia; mas o proposito era firme e decidido, e o meu esforço tambem devia ser, na mesma proporção, decidido e firme. Estudei para isso e para isso encaminhei a minha vida.

Referi-me, ha pouco, á prodigalidade divina para comigo e á generosidade dos homens em que ela se transfórma para beneficiar-me.

Dois anos eram passados sobre esse proposito e, encontrando-me numa das ruas desta capital com o Conselheiro Martim Francisco, a quem eu apenas cumprimentava, cheio de respeito, pela elevada posição, politica e academica, em que se achava investido, chamou-me ele a si e dizendo-me ter visto um trabalho forense por mim escrito, na advocacia 
do Conselheiro Dutra Rodrigues, acrescentou: "estude para defender teses".

Corria eu, então, o meu quarto ano de direito. Dois anos mais, e fazia eu o meu exame do $5 .^{\circ}$ ano, em que tomaram parte, como examinadores, o Conselheiro Furtado, o Conselheiro Duarte de Azevedo e o Dr. Vieira de CarvaLHo, os quais, com suma bondade, elogiaram com ardor as minhas provas.

Ao conferir-me o grau de bacharel em ciencias juridicas e sociais, no dia 30 de outubro de 1875, abraçou-me o Conselheiro FurTado, como era de praxe naquela epoca, e, ao abraçar-me, disse-me ao ouvido: "tire pontos para defender teses".

Aí está, senhores, como a providencia encaminhou a minha defesa de teses, necessaria ao doutoramento que eu pretendia, servindo-se da generosidade desses dois lentes da Faculdade de Direito, aos quais, por gratidão, eu dediquei especialmente as minhas teses, depois de aprovadas pela Congregação.

Ainda não estava completa a ação da Providencia. Para defender teses, e para realizar o meu duplo proposito, conquistando o grau de doutor e a cadeira de lente, eu precisava permanecer nesta capital, e, sem recursos, como acima disse, não poderia faze-lo.

Pois bem, senhores, apenas formado, ofereceu-me o Conselheiro Dutra Rodrigues um lugar no seu acreditado escritorio de advocacia, e nele entrei a trabalhar, com grande vantagem, para mim, material e moral. E depois disso, que já era tanto, ainda não estava desviada a cornucopia das graças. Dois mêses depois, vagava a Promotoria $\mathrm{Pu}-$ blica desta Capital, então exercida pelo Dr. João Pereira Monteiro; e o mesmo Conselheiro Dutra Rodrigues e o Dr. Sebastião José Pereira, então presidente da Provincia de São Paulo, espontaneamente, e sem me ouvirem, tomaram a deliberação combinada de fazer a minha nomeação para esse cargo. 
Fui nomeado promotor publico, desta Capital, em 24 de janeiro de 1876; e com esse cargo, e com o lugar que tinha no escritorio de advocacia, estava eu com a permanencia nesta Capital perfeitamente garantida, em condição de recomendar-me pelos meus serviços, e assim suficientemente habilitado a prosseguir na realisação do meu proposito, assentado no segundo ano do curso academico.

Assumi a promotoria, e tres mêses depois devidamente preparado para, sem vacilações, exercer as funções do cargo, requeri á Faculdade de Direito que me désse pontos para defesa de teses.

Estudei os pontos, que me foram dados, redigi as teses sobre todas as disciplinas juridicas, escrevi a dissertação sobre um dos pontos dados, e defendi-as nos dias 10 e 12 de agosto de 1876 , dias que pela Congregação me foram designados, sendo aprovado pela unanimidade de votos dos meus julgadores.

No dia 9 de novembro de 1876, dia tambem designado pela Congregação, recebi o grau de doutor em Direito, e, com ele, a honra especial de sentar-me no Doutoral da Faculdade, logo abaixo do lente mais novo, que era então o Dr. Joaquim Augusto de Camargo.

Nesse dia, ali estive sentado, e confesso, senhores, que me sentia pequeno diante das grandes figuras daquele cenaculo, que eram, então, os conselheiros Pires da Mota, Furtado de Mendonģa, Silva Carrão, Ramalho, Chrispiniano, Martim Francisco, José Bonifacio e os doutores Justino de: Andrade, Falcão Filho, João Theodoro, Sá e Benevides, Leoncio de Carvalho, Dutra Rodrigues, Vieira de Carvalho e Joaquim Augusto de Camargo.

Estava, pois, vencida, e vencida galhardamente, a metade do meu proposito, assentado no segundo ano do curso academico, e prosseguido com constancia e com firmeza até a sua realização.

Restava a segunda metade, a conquista da cadeira de lente da Faculdade. Essa conquista durou cinco anos depois de iniciada, e foi pontuada de peripecias varias, mas 
todas vencidas, graças ao esforço constante, e á prodigalidade divina para comigo, sempre desdobrada em generosidades que nunca falharam".

Nesses cinco anos, disputou a almejada cadeira de lente em cinco concursos, em cada um dos quais mais se salientou.

Aberta, em julho de 1877, a vaga de substituto, pela promoção de Sá e Benevides a catedratico, inscreveu-se Dino Bueno em concurso, tendo como opositores LeIte de Morais, Rubino de Oliveira, José Avelino Gurgel do Amaral, Bulhões de Carvalho, Frederico Abranches e Vicente Mamede de Freitas. Decorreu o concurso sem incidentes e o classificado em primeiro lugar, Joaquim de Almeida Leite de MoRAIS, foi o nomeado, por decr. de 24 de agosto de 1878.

Abriram-se, no correr do ano de 1882, quatro concursos.

Para o primeiro apresentaram-se Dino Bueno, Frederico Abranches, Vicente Mamede de Freitas, João Pereira Monteiro, Americo Brasiliense e Luiz Lopes Baptista dos AnJos. Este não apresentou as teses e a dissertação e AMErico Brasiliense, por enfermo, não compareceu. Classificados João Monteiro em primeiro lugar, Vicentre Mamede em segundo e Drno Bueno em terceiro, foi o segundo nomeado, por decreto de 5 de setembro de 1882 .

Inscreveram-se no segundo Dino Bueno, João Monteiro, João Manoel Carlos de Gusmão, Frederico Abranches, Americo Brasiliense, Lopes dos Anjos e Vicente Mamede. Mas somente João Monterro, Dino Bueno e João Manoel Carlos DE Gusmão se submeteram ás provas, sendo nessa ordem classificados. JoÃo MonteIro foi o nomeado, por decreto de 2 de setembro de 1882.

Disputaram a cadeira, no terceiro concurso, AMERIco Brasiliense, Dino Bueno, lopes dos Anjos e João Manuel Carlos de Gusmão Só o primeiro e o ultimo, entretanto, apresentaram teses e dissertação e Americo Brasiliense dE Almeida Mello, classificado em primeiro lugar, foi nomeado, por decr. de 11 de setembro de 1882.

Outros nomes apareceram inscriptos no quarto concurso: Dino Bueno, Brasilio Machado, Lopes dos Anjos, João 
Manoel Carlos de Gusmão e João Mendes de Almeida Junior. Apresentaram teses e dissertação somente Dino Bueno, Brasilio Machado e Lopes dos AnJos, nesta mesma ordem classificados. Obteve a nomeação Dino Bueno, pelo decreto de 7 de janeiro de 1883.

Empossou-se aos 9 do mesmo mês.

Já então havia exercido, em 1877, o cargo de juiz substituto da comarca da Capital; e, depois, de 1886 a 1887, o de primeiro delegado de policia, tambem desta Capital.

Ocupando a catedra, como lente substituto, revelou-se insigne professor. Expositor sereno e seguro de seus conhecimentos juridicos, ganhou logo a estima de seus discipulos. Alguns destes, e eram Frederico Vergueiro Steidel, M. Pereira Guimarães, Leopoldo Ferreira Monteiro, Miguel de Godoy Moreira e Costa Sobrinho, Urbano Marcondes de Moura, Matheos Chaves da Silva Junior, Joaguim de Souza Campos Junior, Constantino Gongalves Fraga, Octaviano de Anhaia Mello, J. Aristides Monteiro, Juvenal Parada, Gabriel Orlando Teixeira Junqueira e Victor Marques da Silva Ayrosa, reunindo-se em novembro de 1922, afim de festejarem o trigesimo quinto aniversario de sua formatura, lhe enviaram uma preciosa lembrança, acompanhada de um oficio em que faziam votos pela continuação da felicidade e da saude do seu "professor ilustre e amigo sincero, que orientou", escreveram eles, "os nossos primeiros passos na dificil ciencia do direito, com clareza invejavel e erudição extraordinaria, cuja vida tem servido para nós de exemplo de civismo, trabalho e amor á Patria, e cuja estima é um estimulo poderoso".

Promoveu-o a lente cathedratico o decreto de 6 de setembro de 1890 e o de 7 de fevereiro de 1896 lhe designou a cadeira de direito civil, na qual já se mostrara eximio, como membro relator da Comissão Revisora do Projeto do Codigo Civil Brasileiro, em 1893.

Empolgou-o, desde então, a carreira politica, como estes cargos e estas datas indicam: deputado federal, em 1894; secretario do interior no governo de São Paulo, na presiden- 
cia Campos Salles; députado federal por São Paulo e leader da Camara dos Deputados, em 1900 e 1901; diretor do Banco de Credito Real de São Paulo, em 1904; senador estadual paulista, em 1904; diretor da Faculdade de Direito de São Paulo, de 1908 a 1912; vice-presidente da Comissão Diretora do Partido Republicano Paulista, em 1918, tendo exercido a presidencia de 1923 a 1927; presidente da Empresa do Correio Paulistano, de 1918 até 1930; membro da Comissão Elaboradora do Projecto do Codigo do Processo Civil e Comercial do Estado de São Paulo; presidente do Senado do Estado de São Paulo, de 1924 a 1930; presidente do Banco de São Paulo, de 1926 a 1930; presidente do Estado de São Paulo de abril a julho de 1927.

Exerceu a advocacia, com lustre invulgar, de 1875 a 1912, sendo inumeros os seus trabalhos forenses reunidos em folhetos impressos e estampados nas revistas juridicas brasileiras.

Viveu vida longa e feliz, da qual cincoenta e quatro anos dedicados a serviços publicos, e que se encerrou aos 27 de fevereiro de 1931. Casado com a exma. sra. D. Maria Risoleta Vieira Bueno, filha dos falecidos Barões de Taubaté, deixou prole numerosa e brilhante. Sobreviveram-lhe os seus filhos D. Alice Bueno Nogueira, casada com o Dr. Antonio Augusto Gomes Nogueira; Dr. Antonio Bias da Costa Bueno, casado com D. Regina de Miranda Bueno; D. Lucila Bueno Pamplona, casada com Augusto Coelho Pamplona; Dr. Antonio Hermano da Costa Bueno; D. Constança Bueno Pamplona, casada com Luiz Coelho Pamplona; Dr. Antonio Dino da Costa Bueno Junior, casado com D. Maria Lucilla Ferraz Bueno; Dr. Marcio Benjamin da Costa Bueno, casado com D. Genoveva Ribeiro do Valle Bueno e D. Maria Candida Bueno Leonardo, casada com o Dr. Adolpho Carlos Leonardo. Além desses, inumeros netos e bisnetos.

Grande parte dela foi dedicada ao ensino das ciencias juridicas, e á sua aplicação, no triplice aspecto por que desenvolveu a sua atividade como professor, como legislador e como administrador. 
A sua passagem pela diretoria da Faculdade de Direito de São Paulo ficou indelevelmente marcada. Pobremente instalada, como agora ainda acontece, tão pobremente que se poderia dizer de uma pobreza franciscana, o grande estabelecimento de ensino juridico do velho mosteiro franciscano lhe mereceu especial cuidado. Renovou-lhe o mobiliario. Deu-lhe uma fisionomia de mais conforto. Lançou as primeiras linhas do Museu Academico, em vias de realisação nos dias correntes. Planejou o Panteão Academico, em que deviam figurar os retratos dos mais notaveis estudantes de cada geração. Transformou a Sala da Congregação, emprestando-lhe um ambiente mais solene. Tornon mais imponente o Salão Nobre. Deu mais prestancia á Sala das Becas. Substituiu os celebres bancos academicos por mais confortaveis poltronas. Poliu. Isso, quanto ao seu recheio material. No ponto de vista cultural e educacional, fez quanto em si esteve pela elavação do nivel moral e intelectual do ensino.

Foi pena, em verdade, que o seu espirito empreendedor não tivesse encontrado seguidores. Prosseguiu a Faculdade de Direito, sem duvida, a sua alta e gloriosa missão, profundamente nacional.

Professor jubilado, não perdeu de vista a escola juridica em que conquistou as maiores vitorias de sua vida.

Noticiando-lhe o passamento, escreveu O Estado de São Paulo esta nota sugestiva:

"O seu amor á Faculdade, onde formou o seu espirito e onde formou a sua personalidade, permaneceu imutavel. Bastará dizer que em começos de 1929 pediu ao seu filho Dr. Bias Bueno que os netos e netas lhe oferecessem um estandarte, em miniatura, da Faculdade de Direito, e os filhos e filhas uma bandeira nacional, um e outra em seda e bordados a ouro. Para isso deu as dimensões, dizendo que oportunamente conheceriam a razão do seu pedido. De fato, a 15 de dezembro, dia de seu aniversario, foi-lhe oferecida a bandeira e, a 1 de janeiro do ano findo, o estan- 
darte. Pelas dimensões dadas, verificou-se, agora, que o Dr. Dino Bueno queria levar no ataude, sobre a cabeça, o simbolo da Patria e, sobre o peito, a miniatura do glorioso estandarte da escola".

Definiu bem os polos de sua vida. 